\title{
Indoor Cultivation Model of Humidifying and Ventilation Systems for Grey Oyster Mushroom (Pleurotus pulmonarius)
}

\author{
Md. Tariqul Islam ${ }^{1}$ Zarina Zakaria ${ }^{2 *}$, Nasrul Hamidin ${ }^{3}$ and Mohd Azlan Bin Mohd Ishak ${ }^{4}$ \\ 'School of Bioprocess Engineering, Universiti Malaysia Perlis (UniMAP), 02600 Arau, Perlis, Malaysia; \\ mdtareq41@yahoo.com \\ 2Faculty of Engineering Technology, Universiti Malaysia Perlis (UniMAP), 02100 Padang Besar, Perlis, \\ Malaysia; zarinaz@unimap.edu.my \\ ${ }^{3}$ School of Environmental Engineering, Universiti Malaysia Perlis (UniMAP), 02600 Arau, Perlis, Malaysia; \\ nasrulhamidin@unimap.edu.my \\ ${ }^{4}$ Faculty of Applied Sciences, Universiti Technology MARA (UiTM), 02600 Arau, Perlis, Malaysia; \\ azlanishak@perlis.uitm.edu.my
}

\begin{abstract}
Objectives: The current study investigated the effects of different environmental conditions on mushrooms morphology, moisture contents and yields to find out the most efficient way for indoor cultivation with maximum yield and morphology. Methods/Statistical Analysis: In this study, Pleurotus pulmonarius was cultivated in ambient indoor environment without humidifying and ventilation (System 1), indoor humidifying environment without ventilation (System 2) and indoor humidifying environment with ventilation (System 3). Findings: The highest humidity $90 \%$ was recorded both in System 2 and System 3 but the lowest temperature $26.5^{\circ} \mathrm{C}$ was only recorded in System 3 whereas the lowest humidity $41 \%$ and highest temperature $32^{\circ} \mathrm{C}$ was recorded in System 1. The highest individual weight (202g), numbers of fruitbodies (17), cap diameter $(15 \mathrm{~cm})$, stalk height $(15 \mathrm{~cm})$, outstanding $(39 \%)$ moisture containing fruitbodies and bio-efficiency $(73.6 \%)$ was recorded in System3 which was significantly higher than System 1 and System 2. In System 2, the individual weight $(120 \mathrm{~g})$, numbers of fruitbodies $(13)$, cap diameter $(9 \mathrm{~cm})$, stalk height $(11 \mathrm{~cm})$, outstanding $(19.1 \%)$ moisture containing fruitbodies and bio-efficiency (44.1\%) was recorded which is significantly higher than System 1 but lower than System 3. The strongest correlation of individual weight was found with temperature, humidity, numbers of fruitbodies and moisture contents where the numbers of fruitbodies and moisture contents also had correlation with temperature and humidity. Application/Improvement: This study provides an evidence of significant differences among the cultivation systems where the morphology, quality and yields were started to increase as System $1<$ System $2<$ System 3 . Therefore, the design of System 3 is an effective model and method to optimize and control the indoor environmental factors which is an alternative way for indoor mushroom cultivation with higher yield.
\end{abstract}

Keywords: Environment, Indoor, Mushroom, Optimization, Ventilation

\section{Introduction}

Mushroom cultivation in Malaysia is getting important due to increasing in consumption. This is because mushroom contains considerably high nutritional values and outstanding medicinal properties especially for diabetes and joint pains patient. Mushroom has been part of important component of the human diet for over 200 years $s^{1}$, and it is also widely used in medicine since it has anti-microbial, anti-carcinogenic, anti-tumoral and

${ }^{*}$ Author for correspondence 
anti-oxidant properties ${ }^{2,3}$. Pleurotus species contain high range of protein, carbohydrate, amino acids, polysaccharides and energy ${ }^{4}$, it also contains high potassium to sodium ratio with multivitamin including niacin, riboflavin, vitamin $\mathrm{D}, \mathrm{C}, \mathrm{B} 1, \mathrm{~B} 5$ and $\mathrm{B} 6^{\underline{5}}$. The fruiting bodies of mushrooms have been used for centuries as foods and food flavoring ${ }^{6}$. The demand for mushrooms especially the grey oyster mushroom (Pleurotus sajor-caju) is high because it offers high income to local growers due to its ability to grow and fruiting in tropical and subtropical region like Malaysia. Even though the demand is increased, an attempt to increase production is hampered due to inconsistent environmental conditions during the mushroom growth. Since most of Malaysian mushroom cultivations are outdoor, an attempt to control the environmental factors is more challenges and difficult.

According to Malaysian Meteorological Department (MMD), the weather of Malaysia is generally hot and sunny all over the year especially during February to October. The environment of Malaysia is relatively hot ranges from $28^{\circ} \mathrm{C}$ to $34^{\circ} \mathrm{C}$ in temperature and $50 \%$ to $70 \%$ in relative humidity. Sometimes the temperature can rise up to $41^{\circ} \mathrm{C}$ which caused low relative humidity to $58 \%$ during hot season ${ }^{\mathrm{z}}$. Oyster mushrooms are known to be sensitive to the climatic conditions, favorable temperature $\left(20-25^{\circ} \mathrm{C}\right)$ and humidity (80-90\%) condition enhanced the production of fruiting bodies of Oyster mushroom $\frac{8.9}{}$. Mushrooms are cultivated under ambient conditions designed to suit its growth, but can be found in all highly humid regions between spring and autumn ${ }^{10}$.

Mycelial growth of all Oyster mushrooms can take place between $20^{\circ} \mathrm{C}$ and $30^{\circ} \mathrm{C}$. However, for fruiting, different species have different temperature requirements. Pleurotus spp grows in wide range of temperature $15^{\circ} \mathrm{C}-30^{\circ} \mathrm{C} \frac{11}{}$. Temperatures of $16-19^{\circ} \mathrm{C}$ are recommended during the fruiting period ${ }^{12}$ and $21-25^{\circ} \mathrm{C}$ during the growth phase ${ }^{\frac{13}{3}}$. Agaricus bisporus was successfully cultivated in controlled environment by using climate controlled chamber and ventilated chambers to control temperature and fresh air recirculating ${ }^{14}$. For the Grifolafrondosa, the humidity range for mycelial running $60-70 \%$, for primordia initiation $80-90 \%$, for fruiting development 85 to $95 \%$ were recorded ${ }^{15}$.The maximum yield of oyster mushroom (Pleurotus sajorcaju) was found during rainy seasons, when the relative humidity was nearly 70-90\%ํㅣㄹ ${ }^{16}$. Mushroom needs fresh air for their proper growth ${ }^{17}$ and the maximum yield of
Pleurotus ostreatus was found in "Expouring ventilation system" than conventional ventilation system ${ }^{18}$ where Expouring ventilation system was followed by unit of cooler and ventilation fan. The combination of evaporative cooling and continuous ventilation system provided maximum yield and a suitable environmental condition for growing Lentinus edodes ${ }^{19}$. Recently a study reported that humidifying treatment had influenced the mushroom growth in different stages but no optimized condition had identified 20 .

So, it is obvious that the temperature and humidity of Malaysia weather are far from optimal condition for oyster mushroom cultivation. With the traditional or conventional method used by most cultivators, is difficult to achieve the maximum yield as required ${ }^{21}$. Therefore, this study had conducted to develop a design and an effective method that provides an optimized condition for the maximum growing performance in indoor cultivation of Pleurotus pulmonarius. Growing performance was measured as the basis of environmental conditions and mushrooms morphology, moisture contents and biological efficiency (BE\%).

\section{Materials and Methods}

\subsection{Preparation of Mushroom Growing Bags}

Substrates for growing mushroom bags wereformulated by the mixture of saw dust, rice bran and agricultural lime with the ratio of 100:10:1. About $800 \mathrm{~g}$ substrate mixture was filled in each autoclavable polypropylene bags ( $6 \times 9$ inch) and then the opening parts of the bags were closed by plastic cork, paper, rubber band and cap to protect loss of moisture content from inside the bags ${ }^{22}$. After that, the bags were sterilized at 20 psi pressure and $121^{\circ} \mathrm{C}$ temperatures for 6 hours to kill thespore of bacteria, fungi and other microorganisms $s^{23}$. After sterilization, they were cooled to room temperature and injected with spawn prepared through tissue culture technique. Spawn injected bags were placed vertically for 25-30 days in dark for mycelium colonization. The mycelium colonization was completed when the bags were fully covered by white color mycelium. Then the bags with complete colonization were transferred into a growing room inside a building. Cultivation period was counted from the $1^{\text {st }}$ day of bags were transferred and arranged in the cultivation room. 


\subsection{Design of Indoor Cultivation Room}

The indoor cultivation room was located inside a building at Taman Pauh Indah, Arau, Perlis, with $5.8 \mathrm{~m}$ in length, $4.57 \mathrm{~m}$ in wide and $2.74 \mathrm{~m}$ in height. The wall was made by bricks at one side and gypsum board on the rest of the walls. The room was built by four rows of racks; each rack contained four iron bars distance by $15 \mathrm{~cm}$ from each other and $55 \mathrm{~cm}$ distance between the racks. The room was also built up with roof ventilation system and light in order to facilitate fresh air and maintain proper light intensity respectively Figure 1. The bags were placed horizontally through the racks by using rope and made it tight by cable tie and hanged vertically. 12 bags were arranged in one column of rope by 3 bags in together in 4 parts. A total of 17 columns of rope were used to arrange 200 bags. The columns of rope were arranged at $25 \mathrm{~cm}$ distance from each other in every rack. The distance of the top end bag from the ceiling was $76 \mathrm{~cm}$ and the down end bag from the floor was $30 \mathrm{~cm}$ (Figure 1). This arrangement was followed to maintain and ensure proper environment surrounding of each bag.

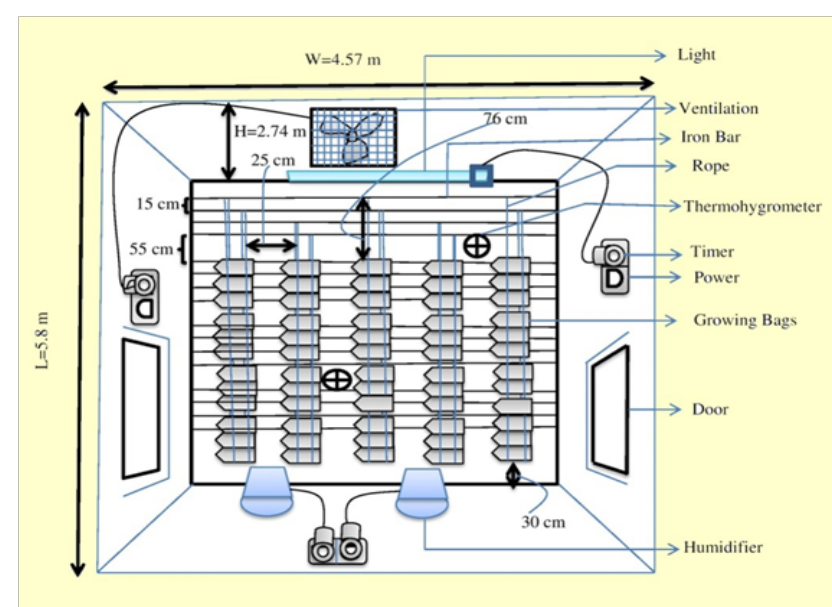

Figure 1. Floor plan and design of indoor mushroom cultivation room with bags arrangement.

\subsection{Experimental Design and Controlled Mushroom Cultivation}

The experimental procedures were designed as ambient indoor environment without humidifying and ventilation (System 1), Indoor humidifying environment without ventilation (System 2), indoor humidifying environment with ventilation (System 3) and indoor ventilating environment without humidifier (System 4). System 4 had no longer performed as in Malaysian environment where the indoor humidity is too low. Therefore, without any artificial humidifying system, mushroom cannot grow in Malaysia. Moreover, ventilation tends to absorb indoor humidity and as result, humidity is being reduced more. So, this study had performed mushroom cultivation in System 1, System 2 and System 3.

\subsection{Ambient Indoor Environment without Humidifying and Ventilation (System 1)}

The complete colonization bags were transferred into the growing room and arranged as shown in Figure 1. The indoor environment was maintained naturally without any humidifying and ventilation throughout the cultivation period. Three thermohygrometers were placed in three different positions inside the room for continuous monitoring of temperature and humidity. After maturation of fruitbodies, the mushrooms were harvested and the data of morphology, moisture contents and yields were recorded.

\subsection{Indoor Humidifying Environment without Ventilation (System 2)}

In humidifying environment without ventilation system, the duration of humidifying was optimized in order to maintain the humidity values ranging between $80-90 \%$ by only humidifier. For this, a single humidifier(TAY-RING TL-3600, TAIWAN) was placed in the middle position between two racks and run to achieve maximum humidity surrounding the rack from initial range to higher than $90 \%$. After that, the humidifying process was stopped and then, the humidity was monitored until the reading dropped to lower than $80 \%$. The changes of humidity with time were measured at 5 minutes interval by Hygro-thermometer (HTC-1, Malaysia). The same procedure was used in all 4 replicates. The data from all replicates were analyzed and a graph was plotted using duration (Minutes) of humidifying and after humidifying on the $\mathrm{X}$-axis while the percentages of humidity (\%) value on the Y-axis to obtain the equation for by which optimized the duration of humidifying for maintaining $80-90 \%$ of humidity.

Then the complete colonization bags were transferred into the growing room and arranged as shown in Figure 1. In this treatment, the indoor humidity was artificially maintained from $80 \%$ to $90 \%$ by using humidifier. The humidifier was operated at duration suggested from optimized results Table 1 obtained from optimization process mentioned earlier. The humidifier was controlled 
by fixing with timer (DG-1120, Malaysia) at 20 minutes running and 65 minutes interval. Thermohygrometer was placed inside the room for continuous monitoring of temperature and humidity. After maturation, the fruiting body was harvested and data was recorded according to its morphology, moisture contents and yield.

\subsection{Indoor Humidifying Environment with Ventilation (System 3)}

In humidifying environment with ventilation system, the duration of humidifying was optimized in order to maintain the humidity values ranging between $80-90 \%$ by using humidifier and ventilation. For this, a single humidifier was placed in the middle position between two racks and run to achieve maximum humidity surrounding the rack from initial range to higher than $90 \%$ with continuous roof ventilation. After that, the humidifying process was stopped and then, the humidity was monitored until the reading dropped to lower than $80 \%$. The changes of humidity with time were measured at 5 minutes interval. The same procedure was used in all 4 replicates. The data from all replicates were analyzed and a graph was plotted using duration (Minutes) of humidifying and after humidifying on the X-axis while the percentages of humidity (\%) value on the Y-axis to obtain the equation for by which optimized the duration of humidifying for maintaining $80-90 \%$ of humidity.

Then the complete colonization bags were transferred into the growing room and arranged as shown in Figure 1. In this treatment, the indoor humidity was artificially maintained between $80 \%$ to $90 \%$ by using humidifier and room ventilation. The humidifier and ventilation was operated at duration suggested from optimized results (Table 1) obtained from optimization process mentioned earlier. The humidifier was controlled by fixing with timer at 25 minutes running and 35 minutes interval. Thermohygrometer was placed inside the room for continuous monitoring of temperature and humidity. After maturation, the fruiting body was harvested and data was recorded according to its morphology, moisture contents and yield.

\subsection{Data Collection}

\subsubsection{Environment Factors}

As temperature and humidity are the basic requirements to stimulate the growth of mushroom, these factors were regularly monitored throughout the investigation period.
The maximum and minimum of indoor temperature and humidity were regularly recorded on daily basis during the cultivation.

\subsubsection{Morphology and Moisture Contents}

The morphology of the mushrooms including Individual Weight (IW), Numbers of Fruiting Bodies (NFB), Cap Diameter (CD) and Stalk Height (SH) were collected from the harvested mushrooms. The weight of mushrooms was measured by weighing machine as gram (g) then the number of fruitbodies was counted. The cap size and stalk height were measured as centimeter $(\mathrm{cm})$ of each fruiting body by metering scale.

The Moisture Content (MC) of mushrooms fruitbodies was determined by using a fivelevel Likert scale ${ }^{24}$ frequently the use of various parametric methods such as analysis of variance, regression, correlation are faulted because: (aincluding from 1 to 5 as very low, low, good, excellent and outstanding respectively on the basis of softness, hardness and dryness of fruitbodies which depends on the percentages of moisture content in fruitbodies. The moisture content of 50-60\%, 60-70\%, 70-80\%, 80-85\%, and $85-90 \%$ were classified as very low (Scale 1), low (Scale 2), good (Scale 3), excellent (Scale 4) and outstanding (Scale 5), respectively, for this the mushrooms fruitbodies were dried by electronic Oven to dry out the moisture and calculated by referring to Equation 2.1

$M C(\%)=\frac{\text { weight of fresh fruitbodies }- \text { Dry weight of fruitbodies }}{\text { weight of fresh fruitbodies }} \times 100 \%(2.1)$

\subsubsection{Yield}

The yield was determined as bio-efficiency (BE\%) to find out the maximum percentages and highest yield of mushrooms. The total yield and bio-efficiency was calculated by following Equation 2.2 2 .

$$
\text { BE \% }=\frac{\text { Weight of fresh fruitbodies }}{\text { Weight of dry substrate }} \times 100 \%(2.2)
$$

\subsection{Statistical Analysis}

Descriptive statistics was applied to determine the maximum, minimum, mean, and Standard Deviation (SD) 
of collected data. Analysis of Variance (ANOVA) techniques was employed to test the overall significance of data, where variations with a probability level of $\mathrm{p}<0.05$ were considered as significant. Correlation method was applied to find out significant relationship among the variables ${ }^{26}$. All of the statistical calculations were executed using SPSS 17.0.

\section{Results}

\subsection{Optimize Humidifying Duration}

\subsubsection{Optimize Humidifying Duration of System 2}

The data from the optimization process of System 2 was plotted using duration of humidifying and after humidifying (Minutes) on the $\mathrm{X}$-axis while the percentages of humidity (\%) value on the $\mathrm{Y}$-axis and obtained two equations one for humidity increasing and another one for humidity decreasing Figure 2.

For increasing humidity, a graph equation was obtained as Equation (3.1) with the correlation coefficient, $\mathrm{R}^{2}$ of 0.9148 which is acceptable as the value closed to 1 .

$$
y=0.4848 x+73.091(3.1)
$$

Where $\mathrm{y}$ is the value of humidity (\%) and $\mathrm{x}$ is the duration of humidifying (minutes)

For decreasing humidity, a graph equation was obtained as Equation (3.2) with the correlation coefficient, $\mathrm{R}^{2}$ of 0.9511 which is acceptable as the value closed to 1 .

$y=-0.1633 x+101.41(3.2)$
Where negative indicated decreasing, $y$ is the value of humidity (\%) and $\mathrm{x}$ is the duration after humidifying (minutes)

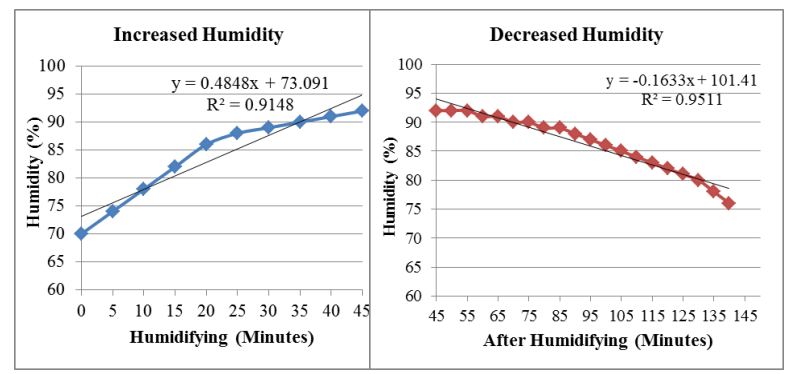

Figure 2. Optimization of humidifying duration in indoor environment without ventilation system (System 2). Values is mean of 4 replicates.

From equation (3.1), the humidifying duration was calculated for $80 \%$ and $90 \%$ humidity and optimized 20.5 minutes humidifying duration to ensure $80-90 \%$ humidity inside the cultivation house. And for decreasing humidity for $90 \%$ and $80 \%$ was also calculated by the equation (3.2) and optimized 60.5 minutes for the decreasing period needed to reach $80 \%$ from $90 \%$ humidity Table 1 . So, for the System 2, the humidifying procedure was optimized as 20 minutes humidifying by 60 minutes interval period throughout the cultivation process.

\subsubsection{Optimize Humidifying Duration of System 3}

The data from the optimization process of System 3 was plotted using duration of humidifying and after humidifying (minutes) on the $\mathrm{X}$-axis while the percentages of humidity (\%) value on the $\mathrm{Y}$-axis and obtained two equations one for humidity increasing and another one for humidity decreasing Figure 3.

Table 1. Calculation of optimized humidifying duration for System 2 and System 3

\begin{tabular}{|l|c|c|c|c|c|c|c|}
\hline System & Value Type & \multicolumn{3}{|c|}{ Increasing } & \multicolumn{3}{c|}{ Decreasing } \\
\hline \multirow{5}{*}{ System 2 } & Equation & \multicolumn{2}{|c|}{$y=0.4848 x+73.091$} & \multicolumn{2}{c|}{$y=-0.1633 x+101.41$} \\
\cline { 2 - 8 } & $\mathrm{y}=$ Humidity (\%) & 80 & 90 & $80-90$ & 90 & 80 & $90-80$ \\
\cline { 2 - 8 } & $\begin{array}{c}\mathrm{x}=\text { Duration } \\
\text { (Minutes) }\end{array}$ & 14.25 & 34.8 & 20.5 & 70.0 & 130.5 & 60.5 \\
\hline \multirow{5}{*}{ System 3 } & Equation & \multicolumn{2}{|c|}{$y=0.4033 \mathrm{x}+67.901$} & \multicolumn{2}{c|}{$y=-0.3297 x+112.59$} \\
\cline { 2 - 8 } & $\mathrm{y}=$ Humidity (\%) & 80 & 90 & $80-90$ & 90 & 80 & $90-80$ \\
\cline { 2 - 7 } & $\begin{array}{c}\mathrm{x}=\text { Duration } \\
\text { (Minutes) }\end{array}$ & 30.0 & 54.8 & 24.8 & 68.5 & 98.9 & 30.3 \\
\hline
\end{tabular}


For increasing humidity, a graph equation was obtained as Equation (3.3) with the correlation coefficient, $R^{2}$ of 0.9712 which is acceptable as the value closed to 1.

$y=0.4033 x+67.901(3.3)$

Where $\mathrm{y}$ is the value of humidity (\%) and $\mathrm{x}$ is the duration of humidifying (minutes).

For decreasing humidity, a graph equation was obtained as Equation (3.4) with the correlation coefficient, $\mathrm{R}^{2}$ of 0.9833 which is acceptable as the value closed to 1 .

$y=-0.3297 x+112.59(3.4)$

Where negative indicated decreasing, $y$ is the value of humidity (\%) and $\mathrm{x}$ is the duration after humidifying (minutes).

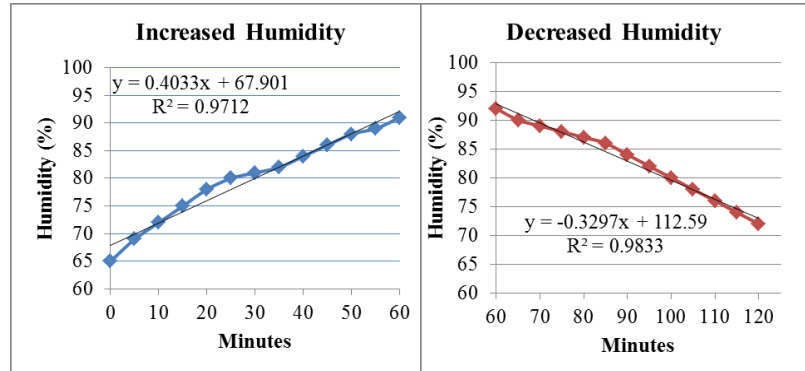

Figure 3. Optimization of humidifying duration in indoor environment with ventilation system (System 3). Values are mean of 4 replicates.

From Equation (3.3), the humidifying duration was calculated for $80 \%$ and $90 \%$ humidity and optimized 24.8 minutes humidifying duration to ensure $80-90 \%$ humidity inside the cultivation house. And for decreasing humidity for $90 \%$ and $80 \%$ was also calculated by the Equation (3.4) and optimized 30.3 minutes for the decreasing period needed to reach $80 \%$ from $90 \%$ humidity (Table 1 ). So, for the System 3, the humidifying procedure was optimized as 25 minutes humidifying by 30 minutes interval period throughout the cultivation process.

\subsection{Indoor Environment}

The temperature and relative humidity persisting in all experimental methods inside the rooms are presented in Table 2(a). Maximum, minimum and mean temperatures were varied greatly among the three different cultivation methods. The lowest mean temperature of $27.5 \pm .6^{\circ} \mathrm{C}$ and highest mean humidity of $89.1 \pm 2.9 \%$ was observed in
System-3 whereas the highest temperature of $30.1 \pm .9^{\circ} \mathrm{C}$ and lowest mean humidity of $64.4 \pm 8.7 \%$ was observed in System 1. The mean temperature of System-2 was $28.9 \pm .7^{\circ} \mathrm{C}$ which was lower than System-1 but higher compared to System 3. Whereas the mean humidity of System-2 was $84.3 \pm 3.6 \%$ which was higher than System 1 but also lower than System-3 (Table 2(a)). The overall mean temperature and humidity were shown significantly difference in One-way ANOVA where the significance level was $\mathrm{p} \otimes 0.05$ Table 2(b).

\subsection{Morphology and Moisture Contents}

For the morphology results, the highest individual weight (202g) and fruit body numbers (17) were obtained in System 3 at $74.49 \mathrm{~g}$ and 6.15 mean value respectively. On the contrary, the lowest individual weight $(61 \mathrm{~g})$ and fruit body numbers (12) was found in System 1 at 29.9g and 5.3 mean value respectively. The maximum individual weight of System 2 was $120 \mathrm{~g}$ with mean $62.36 \mathrm{~g}$, which was higher than System 1 but lower than System 3. On the other hand, the maximum numbers of fruitbody of System 2 was 13 which were also higher than System 1 but lower than System3. The mean numbers of fruitbody of System 2 was found 7.24 which were higher than System 1 and System 3 Table 3.

The individual weight and numbers of fruitbody of mushroom were shown statistically significant results in One-way ANOVA where the significance level was $p \nabla$ 0.05 Table 4. Although the mean numbers of fruitbody in System 2 was higher than System 3 but the mean individual weight of System 3 was higher than System 2. It's happened because the fruitbodies of System 3 contained more moisture than System 2 due to the low temperature and high humidity of System 3.

The highest cap diameter $(15 \mathrm{~cm})$ and stalk height $(15 \mathrm{~cm})$ was found in System-3 at $7.42 \mathrm{~cm}$ and $6.89 \mathrm{~cm}$ mean value respectively. Whereas the lowest cap diameter $8.40 \mathrm{~cm}$ and stalk height $5 \mathrm{~cm}$ was found in System 1 with mean $4.26 \mathrm{~cm}$ and $3.75 \mathrm{~cm}$ respectively. The cap diameter and stalk height of System 2 was found $9.50 \mathrm{~cm}$ and 11.50 $\mathrm{cm}$ with mean $5.59 \mathrm{~cm}$ and $6.51 \mathrm{~cm}$ respectively which were greater than System 1 but lower than System 3 (Table 3). The cap diameter and stalk height of mushroom were shown statistically significant results in One-way ANOVA where the significance level was $\mathrm{p} \otimes 0.05$ Table 4 .

The outstanding $85-90 \%$ moisture containing fruitingbody had found both in System 2 and System 3 but the 
Table 2(a). Descriptive statistics of temperature and humidity in different environmental conditions during cultivation

\begin{tabular}{|c|c|c|c|c|c|c|}
\hline Parameter & $\begin{array}{c}\text { Environmental } \\
\text { Conditions }\end{array}$ & Mean & Std. Deviation & Std. Error & Minimum & Maximum \\
\hline \multirow{3}{*}{ Temperature } & System 1 & 30.1 & .89 & .063 & 29.00 & 32.00 \\
\hline & System 2 & 28.9 & .69 & .048 & 28.00 & 30.00 \\
\hline & System 3 & 27.5 & .64 & .032 & 26.50 & 29.50 \\
\hline \multirow{3}{*}{ Humidity } & System 1 & 64.39 & 8.74 & .618 & 41.00 & 77.00 \\
\hline & System 2 & 84.22 & 3.61 & .255 & 80.00 & 90.00 \\
\hline & System 3 & 89.06 & 2.91 & .145 & 80.00 & 90.00 \\
\hline
\end{tabular}

Table 2(b). One way ANOVA of temperature and humidity in different environmental conditions during cultivation

\begin{tabular}{|c|c|c|c|c|c|c|}
\hline Parameter & Compare & Sum of Squares & Df & Mean Square & $\mathrm{F}$ & Sig. \\
\hline \multirow{2}{*}{ Temperature } & Between Groups & 861.4 & 2 & 430.7 & \multirow{2}{*}{822.8} & \multirow{2}{*}{.000} \\
\hline & Within Groups & 417.2 & 797 & .52 & & \\
\hline \multirow{2}{*}{ Humidity } & Between Groups & 82819.7 & 2 & 41409.9 & \multirow{2}{*}{1561.8} & \multirow{2}{*}{.000} \\
\hline & Within Groups & 21132.1 & 797 & 26.5 & & \\
\hline
\end{tabular}

Table 3. Descriptive table of morphology and quality of fruitingbody in three different environmental cultivation systems

\begin{tabular}{|c|c|c|c|c|c|}
\hline Parameters & Environmental Conditions & Mean & Std. Deviation & Minimum & Maximum \\
\hline \multirow{3}{*}{ Individual Weight (IW) } & System 1 & 29.89 & 16.89 & 3.00 & 61.00 \\
\hline & System 2 & 62.36 & 19.34 & 14.00 & 120.00 \\
\hline & System 3 & 74.49 & 40.078 & 12.00 & 202.00 \\
\hline \multirow{3}{*}{$\begin{array}{l}\text { Numbers of fruit body } \\
\text { (NFB) }\end{array}$} & System 1 & 5.30 & 2.32 & 1.00 & 12.00 \\
\hline & System 2 & 7.24 & 2.77 & 1.00 & 13.00 \\
\hline & System 3 & 6.15 & 3.71 & 1.00 & 17.00 \\
\hline \multirow{3}{*}{ Cap diameter (CD) } & System 1 & 4.26 & 1.63 & 1.00 & 8.00 \\
\hline & System 2 & 5.59 & 1.95 & 1.00 & 9.00 \\
\hline & System 3 & 7.42 & 1.82 & 3.00 & 15.00 \\
\hline \multirow{5}{*}{ Stalk height (SH) } & System 1 & 3.75 & .87 & 2.00 & 5.00 \\
\hline & System 2 & 6.51 & 2.17 & 2.00 & 11.00 \\
\hline & System 3 & 6.89 & 1.38 & 3.00 & 15.00 \\
\hline & System 2 & 3.53 & .98 & 1.00 & 5.00 \\
\hline & System 3 & 4.11 & .87 & 2.00 & 5.00 \\
\hline
\end{tabular}


percentages value of System 3 was 39\% which was higher than System 2 (19.2\%). The excellent 80-85\% moisture containing fruitbodies had also found both in System 2 and System 3 but the percentages value of System 3 had recorded 38\% which was higher than System 2 (27.1\%). No outstanding and excellent moisture containing fruitbodies had found in System 1 but good quality (24\%) that contained $70-80 \%$ moisture was found in these cultivation Systems. Moreover, the low as $60-70 \%$ and very low as $50-60 \%$ moisture containing fruitbodies had found System 1 and System 2. Only 5\% low moisture containing fruitbodies had found in System 3 but no very low had recorded Figure 4 . The moisture contents of mushroom had also shown statistical significant in One-way ANOVA where the significance level was $p \otimes 0.05$ Table 4 .

\subsection{Correlation}

Mushroom production is very sensitive to environmental factors especially the temperature and humidity.In this study, the temperature and the humidity were showed significant negative correlation to each other, where humidity showed significant positive correlation among mushrooms individual weight, fruit body numbers, cap diameter, stalk height and quality. That means the higher range of humidity is associated with higher score of those parameters. On the other hand, temperature showed significant negative correlation with those parameters which clearly indicated that the higher range of temperature is associated with lower score of mushrooms morphology. The highest positive pearson correlation coefficient (.678) was found in humidity and moisture contents whereas The highest negative pearson correlation coefficient (-.617) was found in temperature and moisture contents Table 5.

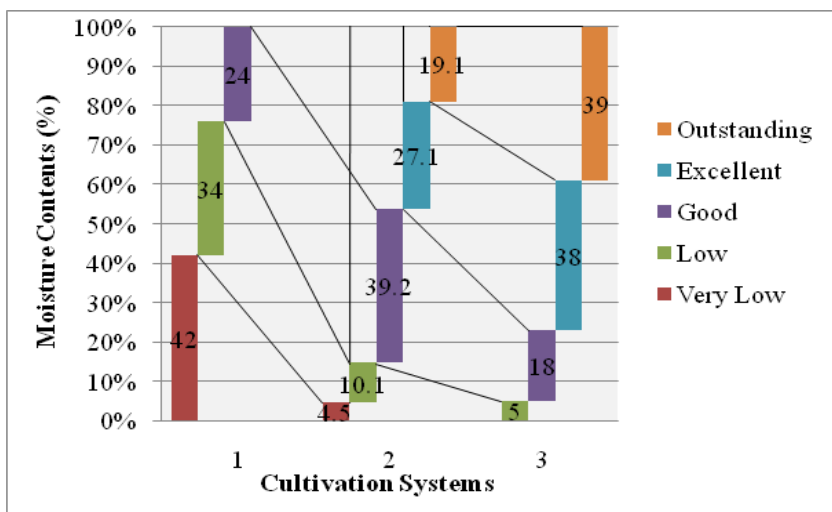

Figure 4. Percentages of moisture contents of $\mathrm{P}$. pulmonarius fruitbodies in different cultivation systems.

\subsection{Yield}

The lowest bio-efficiency (2.8\%) had found in the cultivation of System 1 and it was dramatically increasing in another two cultivation systems where System 3 had recorded the highest $73.6 \%$ bio-efficiency. In System 3, the highest mean value of bio-efficiency had $40.5 \%$, whereby the lowest mean $12.3 \%$ recorded in System 1. The mean value of bio-efficiency $25.5 \%$ had found in the cultivation of System 2 which was higher than System 1 but lower than System 3. Figure 5 represented the variation of bioefficiency among the different cultivation systems.

Table 4. One-way ANOVA Analysis for morphology and quality of Pleurotus pulmonarius to identify the significant differences among the three different cultivation systems

\begin{tabular}{|c|c|c|c|c|c|c|}
\hline Parameters & Compare & Sum of Squares & Df & Mean Square & $\mathrm{F}$ & Sig. \\
\hline \multirow{2}{*}{ Individual Weight } & Between Groups & 266279.8 & 2 & 133139.9 & \multirow{2}{*}{137.4} & \multirow{2}{*}{.000} \\
\hline & Within Groups & 772040.6 & 797 & 968.7 & & \\
\hline \multirow{2}{*}{$\begin{array}{l}\text { Numbers of fruit } \\
\text { body }\end{array}$} & Between Groups & 377.3 & 2 & 188.7 & \multirow{2}{*}{18.6} & \multirow{2}{*}{.000} \\
\hline & Within Groups & 8096.3 & 797 & 10.2 & & \\
\hline \multirow{2}{*}{ Cap diameter } & Between Groups & 1421.1 & 2 & 710.5 & \multirow{2}{*}{216.8} & \multirow{2}{*}{.000} \\
\hline & Within Groups & 2611.9 & 797 & 3.3 & & \\
\hline \multirow{2}{*}{ Stalk height } & Between Groups & 1378.1 & 2 & 689.1 & \multirow{2}{*}{298.4} & \multirow{2}{*}{.000} \\
\hline & Within Groups & 1840.5 & 797 & 2.3 & & \\
\hline \multirow{2}{*}{ Moisture Contents } & Between Groups & 704.4 & 2 & 352.2 & \multirow{2}{*}{452.01} & \multirow{2}{*}{.000} \\
\hline & Within Groups & 620.2 & 796 & .78 & & \\
\hline
\end{tabular}


Table 5. Correlation between and among with the environmental factors and the morphology of Pleurotus pulmonarius

\begin{tabular}{|c|c|c|c|c|c|c|c|c|}
\hline & & Tem & Hum & IW & NFB & $\mathrm{CD}$ & SH & MC \\
\hline \multirow[t]{2}{*}{ Tem } & PC & 1 & $-.749^{\star *}$ & $-.510^{\star *}$ & $-.141^{\star *}$ & $-.517^{* *}$ & $-.459^{* *}$ & $-.617^{\star x}$ \\
\hline & Sig. & & .000 & .000 & .000 & .000 & .000 & .000 \\
\hline \multirow[t]{2}{*}{ Hum } & PC & $-.749^{\star *}$ & 1 & $.525^{\star *}$ & $.160^{* *}$ & $.522^{\star *}$ & $.581^{\star *}$ & $.678^{* *}$ \\
\hline & Sig. & .000 & & .000 & .000 & .000 & .000 & .000 \\
\hline \multirow[t]{2}{*}{ IW } & $\mathrm{PC}$ & $-.510^{\star *}$ & $.525^{\star *}$ & 1 & $.593^{* *}$ & $.349^{* *}$ & $.289^{* *}$ & $.567^{\star *}$ \\
\hline & Sig. & .000 & .000 & & .000 & .000 & .000 & .000 \\
\hline \multirow[t]{2}{*}{ NFB } & PC & $-.141^{\star *}$ & $.160^{* \star}$ & $.593^{* *}$ & 1 & -.063 & .061 & $.141^{\star *}$ \\
\hline & Sig. & .000 & .000 & .000 & & .075 & .082 & .000 \\
\hline \multirow[t]{2}{*}{ CD } & PC & $-.517^{\star \star}$ & $.522^{\star *}$ & $.349^{* *}$ & -.063 & 1 & $.492^{* *}$ & $.543^{* *}$ \\
\hline & Sig. & .000 & .000 & .000 & .075 & & .000 & .000 \\
\hline \multirow[t]{2}{*}{ SH } & $\mathrm{PC}$ & $-.459^{\star *}$ & $.581^{\star *}$ & $.289^{* \star}$ & .061 & $.492^{\star *}$ & 1 & $.537^{\star *}$ \\
\hline & Sig. & .000 & .000 & .000 & .082 & .000 & & .000 \\
\hline \multirow[t]{2}{*}{ MC } & PC & $-.617^{\star *}$ & $.678^{\star *}$ & $.567^{\star *}$ & $.141^{\star *}$ & $.543^{* *}$ & $.537^{\star *}$ & 1 \\
\hline & Sig. & .000 & .000 & .000 & .000 & .000 & .000 & \\
\hline
\end{tabular}

*. Correlation is significant at the 0.05 level. ${ }^{* *}$. Correlation is significant at the 0.01 level.

"PC - Pearson Correlation, Tem - Temperature, Hum-Humidity, IW - Individual Weight, CD - Cap Diameter, SH - Stalk Height, MC - Moisture Contents"

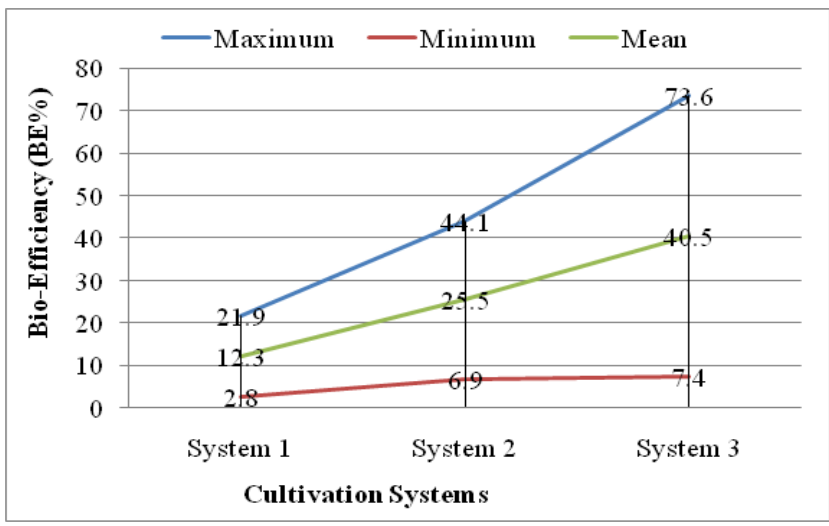

Figure 5: Changing bio-efficiency (BE \%) in three different environmental cultivation systems.

\section{Discussion}

Within these three systems, the mean temperature was varied approximately $1.1-2.5^{\circ} \mathrm{C}$ and the mean humidity were varied approximately $19.9-24.7 \%$ which is shown statistically significant results with One-way ANOVA where the significance level was p『0.05 (Table 2(b)). In System 2, the temperature and humidity were varied 1.05 ${ }^{\circ} \mathrm{C}$ lower and $19.84 \%$ higher from System 1 respectively. Other hand in System 3, the temperature and humidity were varied $2.46^{\circ} \mathrm{C}$ lower and $24.66 \%$ higher from System
1 respectively. So the temperature and humidity of System 3 was $1.41^{\circ} \mathrm{C}$ lower and $4.88 \%$ higher (respectively) than System 2. The lowest indoor temperature $\left(26.5^{\circ} \mathrm{C}\right)$ also found in System 3 whereas, the highest $\left(32^{\circ} \mathrm{C}\right)$ was in System 1. Moreover in System 1 and 2, there was no proper air circulation although the humidity of System 2 was within optimal ranges. Ventilation system provided proper air circulation and improved the indoor air quality by low carbon-dioxide level and thermal comfortable in hot-humid country ${ }^{27,28}$. This result agrees that the evaporative cooling and continuous ventilation system reduced the temperature and increased the relative humidity of air inside a mushroom house $\mathrm{e}^{\frac{19}{}}$, which is also supported to the earlier report of ${ }^{14}$. So, this result has shown that it is easy to maintain optimum indoor humidity ranges by using only humidifier but difficult to reduce temperature greatly by only humidifier. Whereas, both humidifying and ventilation system were able to reduce temperature more effective than only humidifying system with proper air circulation.

The morphology including individual weight, numbers of fruitbody, cap size and stalk height started to decrease at humidity lower than $80 \%$ and decreased severely in System 1 which is supported the earlier report $\frac{18}{}$. The main difference between System 1 and System 2 was 
indoor humidity and temperature where in System 2; the NFB was significantly higher than System 1 . On the other hand, the main difference between System 2 and System 3 was indoor temperature and air circulation because in these both systems the humidity was within $80-90 \%$ although mean was quite different but the mean NFB of System 2 was higher than System 3 but not significant. So this current study reported that humidity is more important factor for NFB than temperature and air circulation but has combined effective effects on NFB and morphology. The lowest weight, less numbers of fruitbody and tiny caps were found in less frequent ventilation system whereas high weight, maximum numbers of fruitbody and broad caps were found in frequent ventilation system $^{29}$. So, this study showed strong significant effects of humidifying and ventilation for proper development of mushrooms morphology.

Quality evaluation is generally done with naked eye $\mathrm{e}^{18}$ where excessive moisture content can cause contamination and poor quality, while less moisture content can result in desiccation and poor quality ${ }^{30}$. In this study, the moisture containing fruitbodies had gradually increased with the increased ranges of indoor humidity because lower indoor humidity tends to absorb moisture from the fruitingbodies as a result the fruitingbodies becoming dry and lost its quality. Moreover no significant humidity difference between System 2 and System 3 but System 3 produced better quality than System 2, because System 3 followed by lower temperature and proper air circulation. The mushrooms fruitingbody becoming dry, hard, cap turns into umbrella shape and stalk becoming thickness at humidity lower than $80 \%$ and decreased severely at $60 \%$ or less which is also supported to this present result ${ }^{17}$. This result showed proper moisture containing fruitbodies for the best quality and an indoor cultivation system where the ventilation provides better environmental condition with humidifier for quality improvement than only humidifying system because ventilation system (System 3) maintained lower temperature along with optimum humidity and fresh air recirculation.

Among all the morphological parameters, the highest positive pearson correlation coefficient of individual weight was found in the case of NFB (.593) that means $\mathrm{NFB}$ is the main morphological factor for maximum individual weight. Other parameters like cap diameter, stalk height and moisture contents had also influenced the individual weight where all the morphological parameters had significant positive and negative corre- lation with humidity and temperature respectively. But in the case of NFB, the pearson correlation coefficient was very low that is 0.160 for humidity and 0.141 for temperature. So, NFB of mushroom is partially depends on humidity and temperature. Moreover NFB showed negative correlation with $\mathrm{CD}$ and positive with $\mathrm{SH}$ which meanings that, the decreased length of $C D$ and increased length of $\mathrm{SH}$ are associated with increased NFB but not significant. The mushrooms individual weight, numbers of fruitbody, cap size, stalk height and quality started to decrease at humidity lower than $80 \%$ and decreased severely at $60 \%$ or less $\frac{18}{}$ which is supported to the results of this present study.

In this result (Figure 5), the highest $\mathrm{BE} \%$ was found in System 3 and the lowest was in System 1 which supported to the report where the maximum biological efficiency $P$. ostreatus, $P$. sajor-caju and P. high king was found in $14-27^{\circ} \mathrm{C}$ temperature and $70-80 \%$ relative humidity 25 . Pleurotus species gave very poor yields in high temperature and low relative humidity which is similar to the results of this present study ${ }^{31}$. Although in this present study, the highest BE\% had found in System 3 but the maximum and minimum values were significantly varied among the all bags from $7.4 \%$ to $73.6 \%$. The same variation had also found in System 1and System 2. These findings indicated that, although the environmental condition in each system had constant throughout its cultivation period but all bags were not able to produce equal yield of $\mathrm{BE} \%$. So it is concluded that, low temperature and high humidity had ensured the higher bio-efficiency but not ensured the equal BE\% for all bags and the suggested method (System 3 ) is an effective alternative way for indoor mushroom ( $P$. pulmonarius) cultivation with higher bio-efficiency.

\section{Conclusion}

Based on the result of current study, it could be concluded that mushroom is able to be cultivated in controlled environment. An environmental conditions humidifying with ventilation (System-3) was found very conducive for high yield and quality of $P$. pulmonarious mushroom. This study has also shown significant correlation among the physical (temperature, humidity) and morphological (IW, NFB, CD, SH and MC) factors during mushroom cultivation. So, this study recommends that, the growth performance of $P$. pulmonarius is able to be maximized within indoor environment with optimized range of temperature and humidity at $27-30^{\circ} \mathrm{C}$ and $80-90 \%$ respec- 
tively with fresh air recirculating. For this, the current study provides an effective way to control and optimization process for indoor temperature and humidity which method or system will be an alternative way for the unfavorable environmental ecological region like Malaysia to cultivate Pleurotus pulmonarius with maximum yield and good morphology.

\section{Acknowledgements}

This work was financially supported by the Fundamental Research Grant Scheme (FRGS 9003-00490) from Universiti Malaysia Perlis, Malaysia.

\section{References}

1. Morin E, Kohler A, Baker AR, Foulongne-Oriol M, Lombard V, Nagye LG. Genome sequence of the button mushroom Agaricus bisporus reveals mechanisms governing adaptation to a humic-rich ecological niche. Proceedings of the National Academy of Sciences. 2012; 109(43):17501-6. Crossref PMid:23045686 PMCid:PMC3491501

2. Han S-R, Kim K-H, Lim K-O, Oh T-J. Biological activity analysis of different solvent extracts from Pleurotus ostreatus. Indian Journal of Science and Technology. 2015; 8(26):1-8. Crossref

3. Ozcelik E, Peksen A. Hazelnut husk as a substrate for the cultivation of shiitake mushroom (Lentinula edodes). Bioresource Technology. 2007; 98(14):2652-8. Crossref PMid:17113286

4. Gogavekar SS, Rokade SA, Ranveer RC, Ghosh JS, Kalyani DC, Sahoo AK. Important nutritional constituents, flavour components, antioxidant and antibacterial properties of Pleurotus sajor-caju. Journal of Food Science and Technology. 2014; 51(8):1483-91. Crossref PMid:25114338 PMCid:PMC4108652

5. Ahmed SA, Kadam JA, Mane VP, Patil SS, Baig MM V. Biological efficiency and nutritional contents of Pleurotus florida (Mont.) singer cultivated on different agro-wastes. Nature and Science. 2009; 7(1):44-8.

6. Ma Y, Guan CY, Meng XJ. Biological characteristics for mycelial growth of Agaricus bisporus. Applied Mechanics and Materials. 2014; 508:297-302. Crossref

7. Wafi SR, Ismail MR, Ahmed EM. A case study of the climate factor on thermal comfort for hostel occupants in Universiti Sains Malaysia (USM), Penang, Malaysia. Journal of Sustainable Development. 2011; 4(5):50-56. Crossref

8. Stamets P. Growing Gourmet and Medicinal Mushrooms. Journal of Wild Mushroom. 1993: 11(4):246-53.
9. Van Peer AF, Müller WH, Boekhout T, Lugones LG, Wosten HB. Cytoplasmic continuity revisited: Closure of septa of the filamentous fungus Schizophyllum commune in response to environmental conditions. PLoS One. 2009; 4(6):2-6. Crossref PMid:19543400 PMCid:PMC2695808

10. Akinyele JB, Fakoya, Soji. A, Adetuyi CF. Anti-growth factors associated with Pleurotus ostreatus in a submerged liquid fermentation. Malaysian Journal of Microbiology. 2012; 8(3):135-40.

11. Sarker NC, Hossain MM, Sultana N, Mian IH, Karim A, Amin SMR. Relationship between nutrient content in substrates and economic yield of oyster mushroom (Pleurotus ostreatus). Bangladesh Journal of Mushroom. 2008; 2(1):27-33.

12. Foulongne-Oriol M, Navarro $P$, Spataro C, Ferrer N, Savoie J-M. Deciphering the ability of Agaricus bisporus var. burnettii to produce mushrooms at high temperature $\left(25^{\circ} \mathrm{C}\right)$. Fungal Genetics and Biology. 2014; 73:1-11. Crossref PMid:25234739

13. Largeteau ML, Callac P, Navarro-Rodriguez A-M, Savoie J-M. Diversity in the ability of Agaricus bisporus wild isolates to fruit at high temperature (25 C). Fungal Biology. 2011; 115(11):1186-95. Crossref PMid:22036296

14. Leiva FJ, Saenz-Díez JC, Martínez E, Jiménez E, Blanco J. Environmental impact of Agaricus bisporus cultivation process. European Journal of Agronomy. 2015; 71:141-8. Crossref

15. Miles PG, Chang S-T. Mushrooms: Cultivation, nutritional value, medicinal effect, and environmental impact. Bora Raton, London, New York, Washington DC: CRC Press; 2004.

16. Bano Z, Rajarathnam S. Studies on the cultivation of Pleurotus sajor-caju. Mushroom Journal. 1982; 1(115):243-6.

17. Kurtzman Jr RH. Ventilation for mushroom cultivation: the importance of the needs of mushrooms and of the gas laws. Micologia Aplicada International. 2010; 22(2):63-78.

18. Jang KY, Jhune CS, Park JS, Cho SM, Weon HY, Cheong JC, Choi SG, Sung JM. Characterization of fruitbody morphology on various environmental conditions in Pleurotus ostreatus. Mycobiology. 2003; 31(3):145-50. Crossref

19. Thepa S, Kirtikara K, Hirunlabh J, Khedari J. Improving indoor conditions of a Thai-style mushroom house by means of an evaporative cooler and continuous ventilation. Renewable Energy. 1999; 17(3):359-69. Crossref

20. Islam MT, Zakaria Z, Hamidin N, Ishak MABM. Characteristics of indoor mushroom cultivation of grey oyster (Pleurotus pulmonarius) by different stages of humidifying treatment. World Applied Sciences Journal. 2016; 34(8):1066-75.

21. Rosmiza M Z, DaviesWP, Jabil MJ, Mazdi M. Prospects for increasing commercial mushroom production in malaysia: 
Challenges and opportunities. Mediterranean Journal of Social Sciences. 2016; 7(1 S1):406-15.

22. Islam T, Zakaria Z, Hamidin N, Mohd Ishak MA Bin. A competitive study on higher yield performance in indoor optimized environment and outdoor cultivation of Pleurotus pulmonarius. MAYFEB Journal of Agricultural Science. 2016; 2:13-27.

23. Christopher J, Custodio D. Substrate: Oyster mushroom cultivation. Mushroom Grower's Handbook 1. MushWorld, China; 2004. p. 91-4.

24. Norman G. Likert scales, levels of measurement and the "laws" of statistics. Advances in Health Sciences Education. 2010; 15(5):625-32. Crossref PMid:20146096

25. Uddin MN, Yesmin S, Khan MA, Tania M, Moonmoon M, Ahmed S. Production of oyster mushrooms in different seasonal conditions of Bangladesh. Journal of Scientific Research. 2011; 3(1):161-7.

26. Steel RGD, Torrie JH and DDA. Principles and procedures of statistics. A biometrical approach. New York: McGrawHill; 1997.
27. Al-Tamimi NA. Toward sustainable building design: Improving thermal performance by applying natural ventilation in hot-humid climate. Indian Journal of Science and Technology. 2015; 8(28):1-8. Crossref

28. Taemthong W, Sirikulyanon W. Improving indoor air quality in university buildings in Thailand. Indian Journal of Science and Technology. 2015; 8(29):1-8. Crossref

29. Kong W-S. Descriptions of commercially important Pleurotus species. Oyster mushroom Cultiv Part II Oyster mushrooms. Seoul Heineart Incorporation; 2004. p. 54-61. PMid:14681914

30. Ryu SR, Koo CD. Spatiotemporal changes of temperature and humidity in Lentinula edodes cultivation sheds. Journal of Korean Forestry Society. 2005.

31. Tripathi DP. Mushroom cultivation. New Delhi: Oxford and IBH Publishing Company Pvt Limited; 2005. 